\title{
Burden changes in caregivers of patients with type 2 diabetes: A longitudinal study
}

\author{
M. Suely Alves Costa $^{1}$ (D) | José C. Machado ${ }^{2} \mid$ M. Graça Pereira ${ }^{1}$
}

${ }^{1}$ School of Psychology, University of Minho, Braga, Portugal

${ }^{2}$ Institute of Social Sciences, University of Minho, Braga, Portugal

\section{Correspondence}

M. Suely Alves Costa, School of Psychology, University of Minho, Braga, Portugal.

Email: suelyacosta@gmail.com

Funding information

This study was supported by a scholarship from the Coordination Foundation for the Improvement of Higher Education Personnel/Full Doctoral Program Abroad Financed by CAPES - Brazil (reference number 1010-14)

\begin{abstract}
Aims: The aim of this study was to explore changes in the burden of caregivers of patients with type 2 diabetes experiencing lower limb amputation after surgery.

Background: Literature suggests the burden overload experienced by the caregivers of new amputees is related to an imbalance between the demands and the resources available to these caregivers.

Design: The study followed a longitudinal design assessing caregiver burden at 1 (T1), 7 (T2) and 10 (T3) months after the patient's surgery.

Methods: We used a convenience sample of caregivers of patients with type 2 diabetes amputated with recent lower limb amputation. Data were collected in several hospital units over 18 months in 2014-2015. Sample size included at T1, T2 and T3 110, 101 and 84. Participants completed the socio-demographic questionnaire, the Burden Assessment Scale and the Self-Assessment Caregiver Questionnaire scale.

Results: Caregivers who received help reported lower levels of burden from at baseline with no variation over time. Those caregivers with high levels of stress showed an increase in burden over time, although these results were not significant. Also, caregivers who did not receive help showed higher levels of burden and stress over time compared with the initial baseline that decreased over time.

Conclusion: These results highlight the importance of receiving help, in care, especially among caregivers who care for patients who have undergone major amputation.

\section{KEYWORDS}

amputated, burden, caregivers, chronic disease, diabetes, longitudinal, nurse, nursing, social support, stress
\end{abstract}

\section{1 | INTRODUCTION}

The study of informal caregivers is a particularly relevant topic given the ageing population and prevalence of chronic diseases. Chronic illnesses, such as type 2 diabetes, are associated with long-term complications, including diabetic foot, blindness, renal failure and cardiovascular diseases (Wild, Roglic, Green, Sicree, \& King, 2004). These complications significantly and progressively compromise patient's self-care and work activities (Harris, Eastman, Cowie, Flegal, \& Eberhardt, 1997). International studies show that amputees may become dependent on informal caregivers who often are not prepared for this new and unexpected role (Atherton \& Robertson, 
2006; Medeiros, Bessa, Coura, de França, \& de Sousa, 2012). According to Sequeira (2010), informal care refers to unanticipated, unpaid care and can includes all or only part of caring tasks required by the patient. Consequently, as the disease progresses, higher caregiving demands may contribute to an increase in the informal caregiver's burden (Harris et al., 1997; Sequeira, 2010).

\section{1 | Background}

Amputation may sometimes result in progressive loss of autonomy leading to physical, emotional, social, family and financial distress for informal caregivers (Larson et al., 2008). Caring daily for a person with chronic illness can have harmful effects on the health of those who provide care (Larson et al., 2008). Informal caregivers may present anxious and depressive symptomatology following the evolution of the patient's illness (Gameiro et al., 2008; Neri, Carvalho, Freitas, Cançado, \& Rocha, 2002; and Snaith, 2003). Anxiety in particular can be considered an indicator of burden. Repercussions of the caregiving process include chronic stress (Godwin, Swank, Vaeth, \& Ostwald, 2013) and disorders such as hypertension and angina (White, Mayo, Hanley, \& Wood Dauphinee, 2003).

Several studies found that providing care for long periods of time can be come a source of stress and negatively impact informal caregivers' health (Conde-Sala, Garre-Olmo, Turro-Garriga, Vilalta-Franch, \& López-Pousa, 2010; Figueiredo, 2007; Pearlin, Mullan, Semple, \& Skaff, 1990; Schulz \& Beach, 1999). The relationship between caregiving and caregiver stress and health can be further intensified by factors such as the amount of care the patient requires, the type of family relationship between the two, the cognitive processes of evaluation and coping, as well as the unique individual, social and cultural characteristics of the caregiver.

Having access to a support network is also considered an important element in the context of the stressful process experienced by the caregiver. The affective relationship that the caregiver establishes with the patient; the number of caregiving hours and the level of functional impairment of the dependent individual have an impact on the caregiver stress. Receiving help, in caregiving tasks, allows the caregiver to pause and reduce the burden with direct implications on the quality of life of the caregiver (Garcés, Carretero, Ródenas, \& Alemán, 2010; Limpawattana, Theeranut, Chindaprasirt, Sawanyawisuth, \& Pimporm, 2013). This network of support includes the community with its resources, programmes and family and must consider the nature and frequency of contacts, thus defining the support network as including all the caregiver's relationships (Pearlin et al., 1990). The family and closest members are part of the caregiver's social support helping the primary caregiver with responsibilities, decisions, basic care actions including occasionally replacing the caregiver for short periods of time and performing, most of the time, specific everyday chores such as shopping, paying bills and cashing pensions (Brito, 2009). Caregivers may not always be able to rely on care assistance, Karsch (2003) found that $67.9 \%$ of the caregivers interviewed provided care without any kind of help.

\section{Why is this research or review needed?}

- Assessing the burden and factors influencing this burden is crucial to caregivers' ongoing ability to provide care.

- Results of this study will help develop appropriate interventions to decrease caregiving burden in this population.

\section{What are the key findings?}

- The stress of care and burden decreased overtime, as well as the help in the care. This may indicate a better adaptation of the caregiver.

- Presence of help was associated with decreased burden and stress over time. For this reason, the support must be promoted to prevent burden.

\section{How should the findings be used to influence policy/practice/research/education?}

- According to the results, it would be important to assess the stress levels of informal caregivers, especially those who care for patients with major amputation.

- It would be important to develop health policies that strengthen and broaden informal caregivers' support network.

This study used the theoretical model of caregiver burden (Chou, 2000), which states that the burden of caregiving is expressed both subjectively and objectively. Objective burden includes the actual tasks of caregiving, whereas subjective burden comprises the personal characteristics of the caregiver, such as perception of self-efficacy and self-esteem. This model emphasizes the importance of analysing the burden process prospectively. Burden is related to variables with strong affective ties that can make the act of caring feel less demanding. Moreover, the strategies chosen by the caregiver to deal with certain situations may influence the caregiver's perceived burden.

The caregiver's load model suggests that absence of help and increased stress may be predictors of increased burden over time in caregivers of amputees with type 2 diabetes. According to the literature, there is a shortage of longitudinal studies with informal caregivers.

\subsection{Aims}

The main objective of this study was to explore patterns of change in the burden of informal caregivers of amputees with type 2 diabetes for up to 10 months after amputation. The secondary objective was to examine whether adjustment trends predicted the mean initial status or rates of change in these outcomes, while controlling for help with caring tasks and care stress. 


\section{METHOD}

\section{1 | Design}

This was a descriptive longitudinal study. Participants completed questionnaires at three points in time: 1 month after surgery (T1), 7 months after surgery (T2) and 10 months after surgery (T3). The assessment moments were defined taking into account clinical criteria for the process of adjustment to amputation by the patient (Atherton \& Robertson, 2006).

\section{2 | Setting}

The research was carried out in Portugal in, six hospital units specialized in diabetes care with a formal Multidisciplinary Diabetic Foot Consultation and Vascular Surgery Services.

\section{3 | Participants}

One hundred and ten caregivers took part in this study at T1, 101 at $\mathrm{T} 2$, and 74 at T3. Patients with type 2 diabetes presenting with diabetic foot who were to undergo minor or major amputation surgery were identified by health professionals from the Diabetic Foot Consultation team and invited to participate in this study. Patient consent to contact the caregiver was obtained, on which caregivers were contacted at the presurgical appointment to ascertain their intention to participate in the study and to schedule the first postsurgical interview. Caregivers were duly informed about the nature of the study, data confidentiality and voluntary participation and, if in agreement, signed an informed consent form (Figure 1).

The inclusion criteria were: being a caregiver of a family member with type 2 diabetes presenting with diabetic foot; the patient being referred for major or minor amputation surgery; being older than 18 years old. The study used a convenience sample that included caregivers of type 2 diabetic patients with diabetic foot undergoing amputation surgery.

\section{4 | Data collection}

Data were collected during 18 months in 2014-2015, using the following questionnaires:

- The Socio-demographic Questionnaire developed for this study assessed socio-demographic variables (e.g. age, gender, education) and the caregiver's clinical variables (e.g. physical activity level, presence of chronic disease and help received). Help received was selfreported and defined as instrumental/emotional support received by the family members or neighbours regarding patient's care.

- Self-Assessment Caregiver Questionnaire (CSAQ; Miller, Epstein, Bishop, \& Keitner, 1985; Research Group in Family Health \&

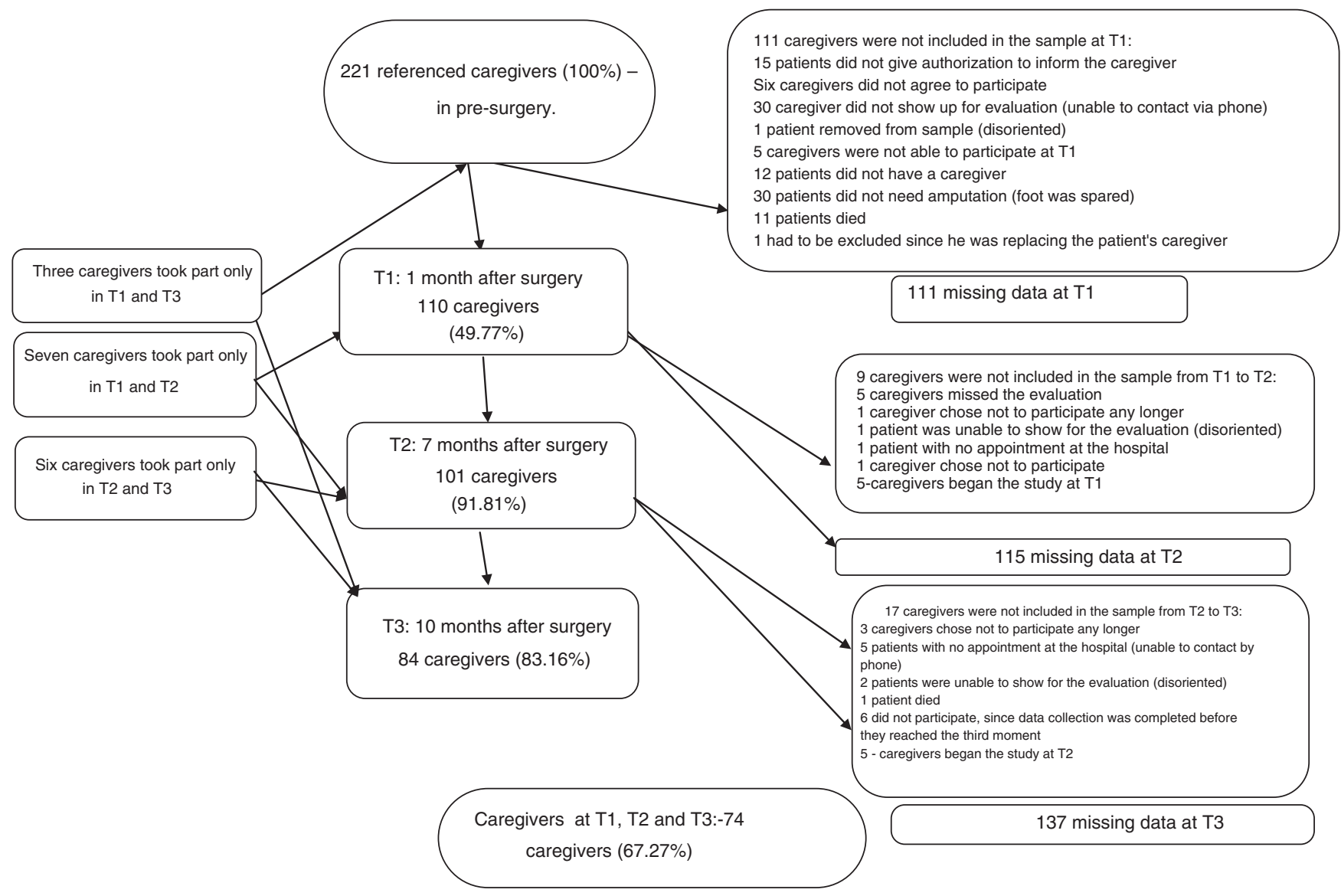

FIGURE 1 Case flow and data collection 
Illness, 2016). This scale consists of 16 items grouped in one factor that includes the positive and negative dimensions of the caregivers' reactions, plus two specific items for their level of stress and health. A high score indicates high levels of stress symptoms due to caregiving activities. The original version showed a Cronbach alpha of 0.78 and in this study, the alpha was 0.82 .

- Burden Assessment Scale (BAS) (Reinhard, Gubman, Horwitz, \& Minsky, 1994; Portuguese version by Cotrim, Azeredo, \& Pereira, 2007). This questionnaire evaluates family exhaustion in objective terms, that is, the demands caregivers feel when caring for someone with restricted activities and resources. The scale consists of 19 items grouped into three subscales: (a) activities restrictions; (b) feelings of worry and guilt; and (c) social burden. The total score is obtained by adding the scores of these three subscales. Higher scores indicate higher rates of burden. Cronbach's alpha ranged from $0.89-0.91$ in the original version. In this study, only the total scale was used. In the Portuguese version the Cronbach's alpha was 0.81 for the total scale (Coutrim et al., 2007), while in this study the alpha was 0.88 .

\section{5 | Ethical considerations}

The study was approved by ethics committees of all the hospitals where data collection took place following to the Declaration of Helsinki.

\section{6 | Data analysis}

The use of Multilevel Modelling (MLM) controls for missing data in a longitudinal design. In addition, MLM can estimate the variation accounted for by factors that are either time invariant, or covary with the outcome of interest (Coffey, Gallagher, Desmond, Ryall, \& Wegener, 2014; Dijkers, 2013; Kozlowski, Pretz, Dams-O'Connor, Kreider, \& Whiteneck, 2013). Data were checked for distribution, missing values and discrepant values following the guidelines established by Tabachnick and Fidell (2013). Descriptive statistics such as means and \% were run to characterize the sample. Physical activity, help in caregiving activities, presence of chronic disease and type of amputation were coded as dichotomous variables ( $0=$ no; $1=$ yes). Differences in socio-demographic and clinical variables among caregivers who dropped out after T1 and those remaining until T3 were examined with a $t$-test for independent samples, the Mann-Whitney test and the chi-squared test.

A Multilevel Model was used to estimate the growth trajectory of each outcome and to determine the effects of change trends over time. Models were separately produced for each outcome using a model-building strategy (Singer \& Willett, 2003). A model (without predictors) was first specified to calculate the intra-class correlation coefficient, which describes the proportion of variance in the results attributable to differences between people. The unconditional growth model (time as the only predictor) was then fitted to estimate initial state and rate of change for the entire sample. Caregiving stress was added as a predictor (time $\times$ stress of caregiving), and a co-variable that varies over time (time $\times$ help in caregiving). Variables as interactions that did not predict a significant proportion of variance $(p<0.05)$ either in the initial state or in rate changes were trimmed to attain the most possible parsimonious model. Significant interaction effects were plotted on $\pm 1 S D$ values of the predictor and moderator using the Interaction software (Soper, 2013).

Analyses were performed using SPSS version 24. A restricted estimate of the maximum probability was used since it provides more accurate results with smaller samples (Kwok et al., 2008). Time was coded as 1, 2 and 3 (T1-T3, respectively). Therefore, the interception of each model represented the value of the result in the initial evaluation. Continuous predictor variables were standardized to improve the interpretation of results (Enders \& Tofighi, 2007; Raudenbush \& Bryk, 2002; Singer \& Willett, 2003). The critical level was set at 0.05 and a nonstructured covariance structure was assumed in each model.

\section{7 | Intruments}

To assess the stress of caring, the CSAQ (Miller et al., 1985) was used. It is a self-report instrument, validated in caregivers of patients with dementia (Epstein-Lubow, Gaudiano, Hinckley, Salloway, \& Miller, 2010). As for the fidelity, in the original version, a Cronbach alpha of 0.78 was obtained. The CSAQ has no Portuguese validation and was used for the first time in a sample of informal caregivers of amputated patients due to the Diabetic Foot and their adaptation to the present population was performed. In this study, one factor solution of the original validation, was respected considering the theoretical coherence and saturation of the items. The Kaiser-Meyer-Olkin (KMO) measurement indicated an adequate sample size for factorial stability $(\mathrm{KMO}=0.752)$ and the Bartlett test was statistically significant $\left(\chi^{2}(153)=606,888, p<0.001\right)$. The only factor extracted explained $29.25 \%$ of the variance of the results. In this adaptation, the items were not organized in the same way as in the original version, since not all items saturated above 0.30 , so we opted to keep only items that saturated above 0.30 and, therefore, items 5 and 15 were eliminated. The final adapted version consists of 14 items with Cronbach's alpha for the total scale of 0.83 (Pereira \& Alves, 2016).

To assess the overload, the BAS (Reinhard et al., 1994; Portuguese version of Cotrim et al., 2007) was used. The scale to be used in assessing the exhaustion of caregivers of patients with mental illness. Cronbach's alpha ranged from 0.89-0.91 in the original version. In the Portuguese version, the Cronbach's alpha was 0.81 for full scale, while in this study, the alpha for the total scale was 0.88 .

\section{RESULTS}

\section{1 | Sample characteristics}

Caregivers' ages ranged from $19-82$ years old (mean $=51.74, S D$ 15.15). Haemoglobin values ranged between 6.20 and 13.10 in the entire sample and in 56 patients with type 2 diabetes was higher than $7.6 \%$, at baseline. The sample's socio-demographic and clinical characterization can be found in Table 1. 
TABLE 1 Descriptive statistics for socio-demographic variables in the three evaluation times

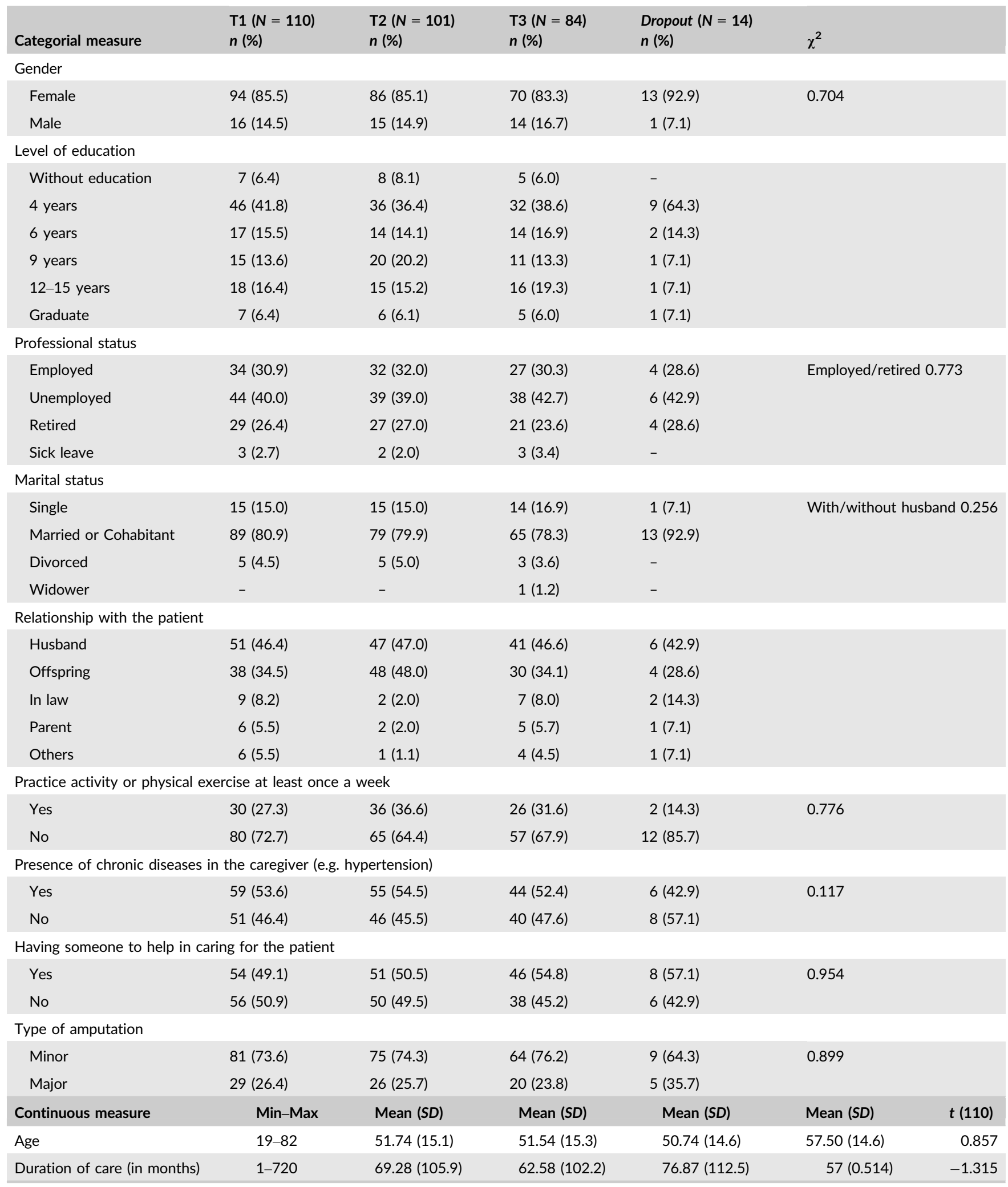

\section{2 | Preliminary analyses}

Of the 110 participants who completed T1, 101(91.81\%) participated at T2 and $84(83.16 \%)$ at T3. Therefore, 74 (67.27\%) completely all the three assessments since some participants only collaborated in one of the time assessments. The main causes of missing data were: caregiver was not at the consultation with the patient $(N=35)$, the patient was not amputated $(N=30)$, the patient did not authorize participation in the study $(N=15)$ and the patient died $N=12$ ). 
TABLE 2 Descriptive statistics for predictor and outcome variable at each time point

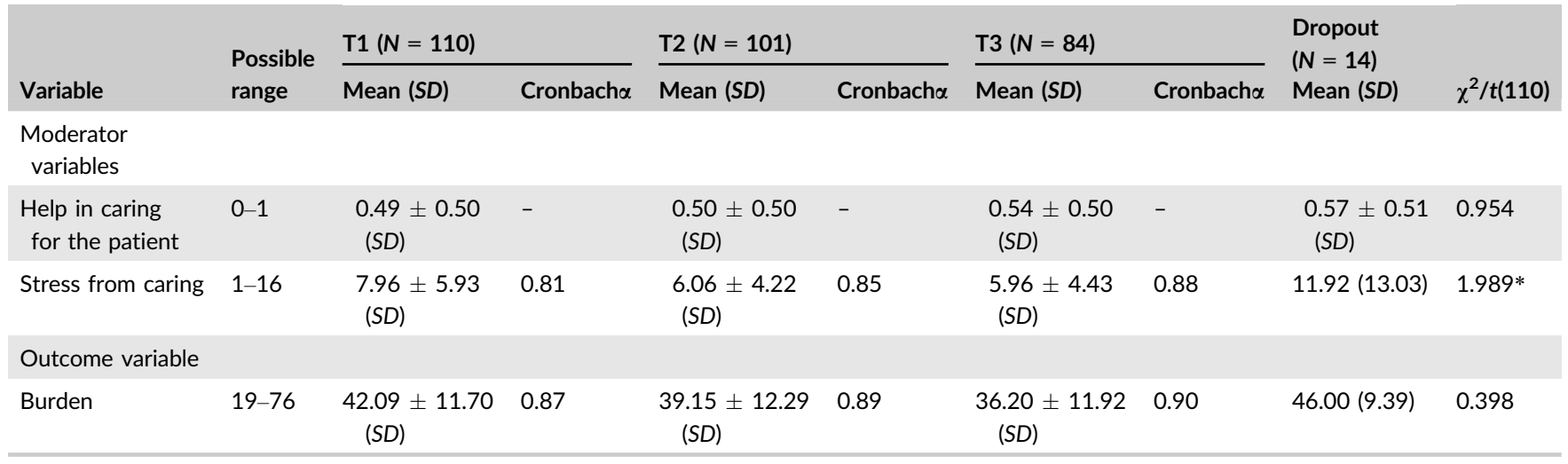

$p \leq 0.05$.

The analysis of means and SDs allowed us to observe that over time there was a decrease in stress levels of caregiving and burden and an increase in the frequency of help in caregiving activities. Cronbach's alphas, means and SDs, mode and frequency for the predictive and outcome measures in T1, T2 and T3 are described in Table 2.

Caregivers who dropped out after T1 did not differ significantly from participants in their socio-demographic (age, length of care, marital status, schooling, work status, kinship level, patient amputation level, caregiving help), clinical (physical activity, hours of sleep per night, diagnosis of chronic illness) and psychological characteristics (stress of caregiving and burden).

\section{3 | Multilevel models}

Intra-class correlation coefficients (ICC) indicated that $35.1 \%$ of total burden variation was attributable to differences between participants. The unconditional growth model for burden revealed an average initial status of 42.217 ( $S E=1.10, p<0.001)$. The average growth trajectory was negative, indicating a decrease in 5.07 points ( $S E=1.54, p=0.001)$ in self-assessed burden (Table 3). Objective burden includes the actual tasks of caregiving, whereas subjective burden comprises the personal characteristics of the caregiver, such as perception of self-efficacy and self-esteem.

TABLE 3 Estimates of fixed effects for the multilevel model predicting burden

\begin{tabular}{|c|c|c|c|c|}
\hline Parameters & Estimates & \multicolumn{2}{|l|}{ SE } & $p$ \\
\hline Intercept & 42.217 & \multicolumn{2}{|l|}{1.102} & $<0.001$ \\
\hline Time & -5.067 & \multicolumn{2}{|l|}{1.537} & 0.001 \\
\hline \multicolumn{2}{|l|}{ Parameters } & Estimates & SE & $p$ \\
\hline \multicolumn{2}{|l|}{ Intercept } & 41.376 & 0.972 & $<0.001$ \\
\hline \multicolumn{2}{|l|}{ Time } & -2.881 & 1.278 & 0.027 \\
\hline \multicolumn{2}{|c|}{ Help in caring for the patient } & -2.718 & 0.926 & 0.004 \\
\hline \multicolumn{2}{|c|}{ Stress from caring } & 0.812 & 0.160 & $<0.001$ \\
\hline \multicolumn{2}{|c|}{ Time $\times$ help in caring for the patient } & 3.402 & 1.296 & 0.010 \\
\hline \multicolumn{2}{|c|}{ Time $\times$ stress from caring } & 1.112 & 0.256 & $<0.001$ \\
\hline
\end{tabular}

\subsubsection{Growth model for effects of help in caregiving on burden}

Caregivers who received help showed lower levels of burden from baseline, with no significant variation over time. Caregivers who did not receive help presented higher level of burden from baseline and showed significant variation over time, i.e., caregivers who did not received help, reported levels of burden that decreased over time (Figure 2).

\subsection{2 | Growth model for effects of stress of caregiving on burden}

Regarding the moderating predictive variable caregiving stress, caregivers with high levels of stress showed an increase in burden over time, although this difference was not significant. Caregivers with

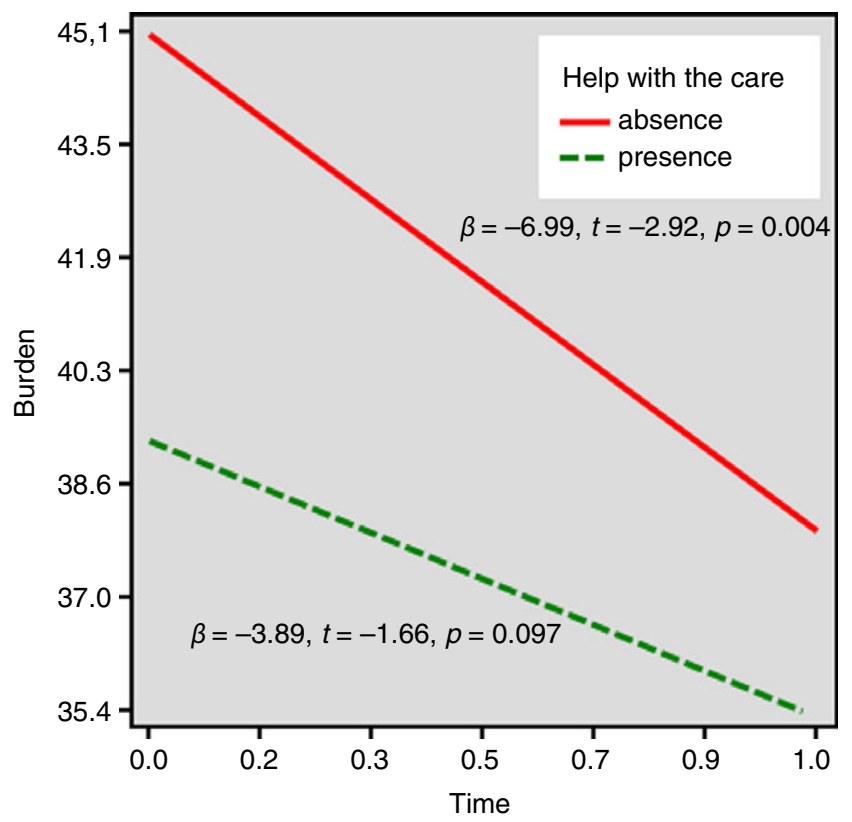

FIGURE 2 Plot of interaction between time and goal pursuit for help in the care 


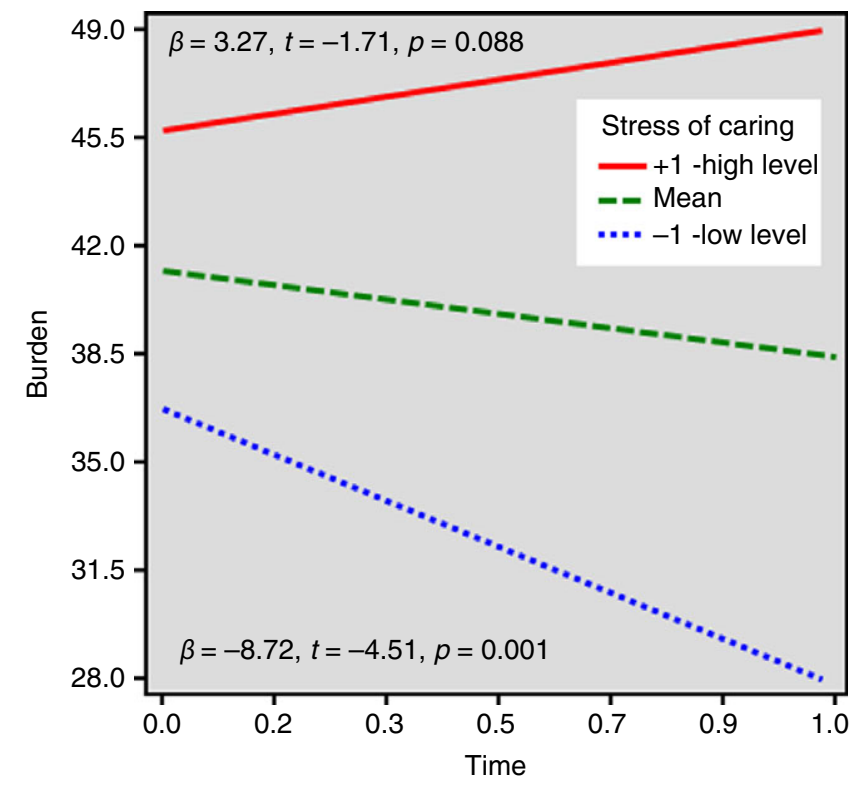

FIGURE 3 Plot of interaction between time and goal pursuit for stress [Colour figure can be viewed at wileyonlinelibrary.com]

low stress levels showed a significant decrease in burden levels over time, i.e., caregivers with low stress levels also showed low levels of burden over time (Figure 3).

\section{DISCUSSION}

This study's goal was to explore patterns of change in the burden of informal caregivers of amputated patients with type 2 diabetes during the first 10 months following amputation. Caregiving stress and burden decreased over time for the whole sample, as well as the the number of caregivers who received help. This result may be related to a better adaptation of the caregiver to the caregiving situation and to the changes caused by amputation. Analysing this study's sample, $74.3 \%$ of the amputations were minor, which may explain patients' autonomy regarding mobility and, consequently, the smaller burden of the caregiver over time. These data corroborate the results of Conde-Sala et al. (2010), Figueiredo (2007), Larson et al. (2008), Pearlin et al. (1990) and Schulz and Beach (1999), who stated that patients with severe limitations due to amputation and the increased care requirements over time lead to physical, emotional, social, family and financial distress in informal caregivers. According to the burden model, there is a correspondence of the objective perceptions of burden with the patient's level of functioning and of the subjective perceptions with the adaptation to the caregiving situation.

The second goal was to analyse the adjustment trajectory of the predictor variables as a function of the outcomes. The hypothesis proposed that lack of help and increased stress over time would predict an increase in burden in caregivers of amputated patients due to type 2 diabetes 10 months after amputation. Regarding the variable caregiving help, the results showed its important role in the health of informal caregivers, since caregivers who received help presented lower levels of burden compared to baseline. Reinforcing the importance of the support network as a moderator/mediator for informal caregivers as described in the burden model, in situations of illness, the availability of social support increases the patient's and family's willingness to adapt and self-esteem (Brito, 2009), since they kept providing care even after 9 months, accompanying the patient to the recommended therapies and being available to collaborate with the health team. With regard to variations over time, in this sample, caregivers who did not have help registered higher levels of burden compared with baseline that decreased significantly over time. It should be noted that the strategies adopted by the caregiver to deal with the patient's situation and the context of the caregiving tasks are related to the burden experienced by the caregiver, as suggested by the Burden model (Chou, 2000).

Caregivers who showed low stress levels also experienced low levels of burden over time. Several studies have identified the psychological impact of prolonged caregiving and the deterioration of the patient, on the caregiver, such as chronic stress (Burgio, Gaugler, \& Hilgeman, 2016; Pinquart \& Sörensen, 2003; Russo, Vitaliano, Brewer, Katon, \& Becker, 1995; Vitaliano, Zhang, \& Scanlan, 2003). However, Neri et al. (2002), Schulz et al. (1997) and Townsend, Noelker, Deimling, and Bass (1989) also present other perspectives of caregiving and point out that not all caregivers develop illnesses or stress exhaustion and that the caregiver may have strong affective ties with the patient and, as such, experience caregiving as less costly (Chou, 2000).

\section{5 | CONCLUSION}

According to the results, it is crucial to evaluate the stress levels of informal caregivers, especially in those who care for patients that underwent major amputation, as well as to develop health policies that help strengthen and broaden the formal and informal support network in order to intervene in the burden stemming from caregiving. Therefore, it is vital that health services assess caregivers of patients with amputated diabetic foot and that health policies provide training, instrumental and social support to allow patients and caregivers to collaborate in the process of caregiving.

The limitations of this study include the exclusive use of selfreport instruments and the fact that caregivers participating in this study were only those who accompanied the patient to the hospital, since many of the caregivers presented at the time of referral did not accompany the patient to the post-surgical consultation, data collection impacting sample size.

\section{ACKNOWLEDGEMENTS}

The authors would like to thank the health professionals from the Multidisciplinary Consultations of the Diabetic Foot at the Santa Luzia Hospital Center in Viana do Castelo, from the Multidisciplinary 
Consultations of the Diabetic Foot at the Tâmega and Sousa Hospital Center, from the Multidisciplinary Consultations of the Diabetic Foot at the Hospital Center of Vila Nova de Gaia/Espinho, from the Multidisciplinary Consultations of the Diabetic Foot at the Hospital Center of Porto, Service of Vascular Surgery at the Hospital of São João, and at the Service of Vascular Surgery of the Hospital of Braga.

\section{CONFLICTS OF INTEREST}

No conflict of interest has been declared by the authors.

\section{AUTHOR CONTRIBUTIONS}

All authors have agreed on the final version and meet at least one of the following criteria (recommended by the ICMJE, http://www. icmje.org/recommendations/):

- substantial contributions to conception and design, acquisition of data or analysis and interpretation of data;

- drafting the article or revising it critically for important intellectual content.

\section{ORCID}

M. Suely Alves Costa iD http://orcid.org/0000-0002-3545-0613

M. Graça Pereira (D) http://orcid.org/0000-0001-7987-2562

\section{REFERENCES}

Atherton, R., \& Robertson, N. (2006). Psychologist adjustment to lower limb amputation amongst prosthesis users. Disability and Rehabilitation, 28, 1201-1209. https://doi.org/10.1080/09638280 600551674

Brito, D. C. S. D. (2009). Caring for caregivers: A case study on the primary caregiver of a patient with chronic renal failure. Psychology in Study. Retrieved from: http://www.scielo.br/pdf/pe/v14n3/v14n3a 22 [Accessed on 05 January 2017].

Burgio, L. D., Gaugler, J. E., \& Hilgeman, M. M. (2016). The Spectrum of Family Caregiving for Adults and Elders with Chronic Illness. UK: Oxford University Press. https://doi.org/10.1093/med:psych/9780199828036.001.0001

Chou, K. R. (2000). Caregiver burden: A concept analysis. Journal of Pediatric Nursing, 15, 398-407. https://doi.org/10.1053/jpdn.2000. 16709

Coffey, L., Gallagher, P., Desmond, D., Ryall, N., \& Wegener, S. T. (2014). Goal management tendencies predict trajectories of adjustment to lower limb amputation up to 15 months post rehabilitation discharge. Archives of Physical Medicine and Rehabilitation, 95, 1895-1902. https://doi.org/10.1016/j.apmr.2014.05.012

Conde-Sala, J. L., Garre-Olmo, J., Turró-Garriga, O., Vilalta-Franch, J., \& López-Pousa, S. (2010). Differential features of burden between spouse and adult-child caregivers of patients with Alzheimer's disease: An exploratory comparative design. International Journal of Nursing Studies, 47, 1262-1273. https://doi.org/10.1016/j.ijnurstu. 2010.03.001

Cotrim, H., Azeredo, Z., \& Pereira, M. G. (2007). Impact of colorectal cancer on patients and caregivers/family: Implications for caring (Doctoral Dissertation). Porto, Portugal: University of Porto.
Dijkers, M. P. (2013). Chasing change: Repeated-measures analysis of variance is so yesterday!. Archives of Physical Medicine and Rehabilitation, 94, 597-599. https://doi.org/10.1016/j.apmr.2012.11.018

Enders, C. K., \& Tofighi, D. (2007). Centering predictor variables in crosssectional multilevel models: A new look at an old issue. Psychological Methods, 12, 121. https://doi.org/10.1037/1082-989X.12.2.121

Epstein-Lubow, G., Gaudiano, B. A., Hinckley, M., Salloway, S., \& Miller, I. W. (2010). Evidence for the validity of the American medical association's caregiver self-assessment questionnaire as a screening measure for depression. Journal of the American Geriatrics Society, 58(2), 387388. https://doi.org/10.1111/j.1532-5415.2009.02701.x

Figueiredo, D. (2007). Family care for dependent elderly. Lisbon: Climepsi Editores.

Gameiro, S., Carona, C., Pereira, M., Canavarro, M. C., Simões, M., Rijo, D., \& Vaz Serra, A. (2008). The depressive symptoms and quality of life in the general population. Psychology, Health \& Diseases. Retrieved from: http://hdl.handle.net/10316/20698 [Consulted on 05 January 2017].

Garcés, J., Carretero, S., Ródenas, F., \& Alemán, C. (2010). A review of programs to alleviate the burden of informal caregivers of dependent persons. Archives of Gerontology and Geriatrics, 50, 254-259. https://doi.org/10.1016/j.archger.2009.04.012

Godwin, K. M., Swank, P. R., Vaeth, P., \& Ostwald, S. K. (2013). The longitudinal and dyadic effects of mutuality on perceived stress for stroke survivors and their spousal caregivers. Aging \& Mental Health, 17, 423-431. https://doi.org/10.1080/13607863.2012.756 457

Harris, M. I., Eastman, R. C., Cowie, C. C., Flegal, K. M., \& Eberhardt, M. S. (1997). Comparison of diabetes diagnostic categories in the US population according to 1997 American Diabetes Association and 1980-1985 World Health Organization diagnostic criteria. Diabetes Care, 20, 1859-1862. https://doi.org/10.2337/diacare.20.12.1859

Karsch, U. M. (2003). Idosos dependentes: Famílias e cuidadores [Dependent seniors: Families and caregivers]. Public Health Journal, 19, 861-866. https://doi.org/10.1590/S0102-311X2003000300019

Kozlowski, A. J., Pretz, C. R., Dams-O'Connor, K., Kreider, S., \& Whiteneck, G. (2013). An introduction to applying individual growth curve models to evaluate change in rehabilitation: A National Institute on Disability and Rehabilitation Research Traumatic Brain Injury Model Systems report. Archives of Physical Medicine and Rehabilitation, 94, 589-96. https://doi.org/10.1016/j.apmr.2012.08.199

Kwok, O. M., Underhill, A. T., Berry, J. W., Luo, W., Elliott, T. R., \& Yoon, M. (2008). Analyzing longitudinal data with multilevel models: An example with individuals living with lower extremity intra-articular fractures. Rehabilitation Psychology, 53, 370. https://doi.org/10.1037/ a0012765

Larson, J., Franzén-Dahlin, Å., Billing, E., von Arbin, M., Murray, V., \& Wredling, R. (2008). The impact of gender regarding psychological well-being and general life situation among spouses of stroke patients during the first year after the patients' stroke event: A longitudinal study. International Journal of Nursing Studies, 45, 257-265. https://doi.org/10.1016/j.ijnurstu.2006.08.021

Limpawattana, P., Theeranut, A., Chindaprasirt, J., Sawanyawisuth, K., \& Pimporm, J. (2013). Caregivers burden of older adults with chronic illnesses in the community: A cross-sectional study. Journal of Community Health, 38, 40-45. https://doi.org/10.1007/s10900-0129576-6

Medeiros, C. C. M., Bessa, G. G., Coura, A. S., de França, I. S. X., \& de Sousa, F. S. (2012). Prevalência dos fatores de risco para Diabetes mellitus de servidores públicos. Revista Eletrônica de Enfermagem, 14, 559-569. https://doi.org/10.5216/ree.v14i3.14430

Miller, I. W., Epstein, N. B., Bishop, D. S., \& Keitner, G. I. (1985). The McMaster Family Assssment Devive: Reliability and validity. Journal of Marital and Family Therapy, 11, 345-356. https://doi.org/10.1111/ j.1752-0606.1985.tb00028.x 
Neri, A. L., Carvalho, V. A. M. L., Freitas, E. V., Cançado, F. A. X., \& Rocha, S. M. (2002). Quality of Life of the caregiver: Psychosocial aspects. Geriatrics and Gerontology Treaty (pp. 778-790). Rio de Janeiro: Guanabara Koogan.

Pearlin, L. I., Mullan, J. T., Semple, S. J., \& Skaff, M. M. (1990). Caregiving and the stress process: An overview of concepts and their measures. The Gerontologist, 30, 583-594. https://doi.org/10.1093/geront/30.5.583

Pereira, M. G., \& Costa, S. (2016). Validation of the Self Assessment Caregiver Questionnaire in a Sample of Caregivers of Type 2 Diabetic Patients with Diabetic Foot. Portugal: Research Group on Health \& IIIness, University of Minho, School of Psychology.

Pinquart, M., \& Sörensen, S. (2003). Differences between caregivers and noncaregivers in psychological health and physical health: a metaanalysis. Psychology and Aging, 18(2), 250-267. https://doi.org/10. 1037/0882-7974.18.2.250

Raudenbush, S. W., \& Bryk, A. S. (2002). Hierarchical linear models: Applications and data analysis methods. UK: Sage.

Reinhard, S. C., Gubman, G. D., Horwitz, A. V., \& Minsky, S. (1994). Burden assessment scale for families of the seriously mentally ill. Evaluation and Program Planning, 17, 261-269. https://doi.org/10.1016/ 0149-7189(94)90004-3

Research Group in Family Health \& Illness (2016). Portuguese Adaptation of the Self-Assessment Caregiver Questionnaire. University of Minho.

Russo, J., Vitaliano, P. P., Brewer, D. D., Katon, W., \& Becker, J. (1995). Psychiatric disorders in spouse caregivers of care recipients with Alzheimer's disease and matched controls: a diathesis-Stress model of psychopathology. Journal of abnormal psychology, 104(1), 197-204.

Schulz, R., \& Beach, S. R. (1999). Caregiving as a risk factor for mortality: The Caregiver Health Effects Study. Journal of the American Medical Association, 282, 2215-2219. https://doi.org/10.1001/jama.282.23. 2215

Schulz, R., Newson, J., Mittelmark, M., Burton, L., Hirsch, C., \& Jackson, S. (1997). Health effects of caregiving: The Caregiver Health Effects Study: An ancillary study of the Cardiovascular Health Study. Annals of Behavioral Medicine, 19, 110-116. https://doi.org/10.1007/ BF02883327
Sequeira, C. (2010). Cuidar de idosos com dependência física e mental. Lisboa, Portugal: Lidel.

Singer, J. D., \& Willett, J. B. (2003). Applied longitudinal data analysis: Modeling change and event occurrence. UK: Oxford University Press. https://doi.org/10.1093/acprof:oso/9780195152968.001.0001

Snaith, R. P. (2003). The hospital anxiety and depression scale. Health and Quality of Life Outcomes, 1, 29. https://doi.org/10.1186/14777525-1-29

Soper, D. S. (2013). Interaction (Version 1.7. 2211) - Computer Program. Fullerton: California State University.

Tabachnick, B. G., \& Fidell, L. (2013). Using multivariate statistics. Boston: Allyn and Bacon.

Townsend, A. L., Noelker, L., Deimling, G., \& Bass, D. (1989). Longitudinal impact of interhousehold caregiving on adult children's mental health. Psychology \& Aging, 4, 393-401. https://doi.org/10.1037/0882-7974. 4.4.393

Vitaliano, P. P., Zhang, J., \& Scanlan, J. M. (2003). Is caregiving hazardous to one's physical health? A meta-analysis Psychological Bulletin, 129, 946. https://doi.org/10.1037/0033-2909.129.6.946

White, C. L., Mayo, N., Hanley, J. A., \& Wood Dauphinee, S. (2003). Evolution of the caregiving experience in the initial 2 years following stroke. Research in Nursing \& Health, 26, 177-189. https://doi.org/10. 1002/nur.10084

Wild, S., Roglic, G., Green, A., Sicree, R., \& King, H. (2004). Global prevalence of diabetes: Estimates for the year 2000 and projections for 2030. Diabetes Care, 27, 1047-1053. https://doi.org/10.2337/diaca re.27.5.1047

How to cite this article: Costa MSA, Machado JC, Pereira MG. Burden changes in caregivers of patients with type 2 diabetes: A longitudinal study. J Adv Nurs. 2018;74:2322-2330.

https://doi.org/10.1111/jan.13728

The Journal of Advanced Nursing (JAN) is an international, peer-reviewed, scientific journal. JAN contributes to the advancement of evidencebased nursing, midwifery and health care by disseminating high quality research and scholarship of contemporary relevance and with potential to advance knowledge for practice, education, management or policy. JAN publishes research reviews, original research reports and methodological and theoretical papers.

For further information, please visit JAN on the Wiley Online Library website: www.wileyonlinelibrary.com/journal/jan

Reasons to publish your work in JAN:

- High-impact forum: the world's most cited nursing journal, with an Impact Factor of 1.998 - ranked 12/114 in the 2016 ISI Journal Citation Reports () (Nursing (Social Science)).

- Most read nursing journal in the world: over 3 million articles downloaded online per year and accessible in over 10,000 libraries worldwide (including over 3,500 in developing countries with free or low cost access).

- Fast and easy online submission: online submission at http://mc.manuscriptcentral.com/jan.

- Positive publishing experience: rapid double-blind peer review with constructive feedback.

- Rapid online publication in five weeks: average time from final manuscript arriving in production to online publication.

- Online Open: the option to pay to make your article freely and openly accessible to non-subscribers upon publication on Wiley Online Library, as well as the option to deposit the article in your own or your funding agency's preferred archive (e.g. PubMed). 